\title{
Corrigendum: Validation of the German Version of the Music- Empathizing-Music-Systemizing (MEMS) Inventory (Short Version)
}

\section{OPEN ACCESS}

Approved by:

Frontiers In Behavioral Neuroscience Editorial Office,

Frontiers Media SA, Switzerland

*Correspondence:

Urs M. Nater

urs.nater@univie.ac.at

Received: 10 September 2018 Accepted: 11 September 2018

Published: 28 September 2018

Citation:

Linnemann A, Kreutz G, Gollwitzer M and Nater UM (2018) Corrigendum: Validation of the German Version of

the Music-Empathizing-MusicSystemizing (MEMS) Inventory (Short

Version).

Front. Behav. Neurosci. 12:228 doi: 10.3389/fnbeh.2018.00228

\author{
Alexandra Linnemann ${ }^{1}$, Gunter Kreutz ${ }^{2}$, Mario Gollwitzer ${ }^{3}$ and Urs M. Nater ${ }^{4 *}$ \\ ${ }^{1}$ Department of Psychiatry and Psychotherapy, University Medical Center Mainz, Mainz, Germany, ${ }^{2}$ Department of Music, \\ School for Linguistics and Cultural Studies, Carl von Ossietzky Universität Oldenburg, Oldenburg, Germany, ${ }^{3}$ Chair of Social \\ Psychology, Department Psychology, Ludwig-Maximilians-Universität Munich, Munich, Germany, ${ }^{4}$ Clinical Psychology, \\ Department of Psychology, University of Vienna, Vienna, Austria
}

Keywords: cognitive style, emotion regulation, music listening, music preference, personality, use of music

\section{A Corrigendum on}

Validation of the German Version of the Music-Empathizing-Music-Systemizing (MEMS) Inventory (Short Version)

by Linnemann, A., Kreutz, G., Gollwitzer, M., and Nater, U. M. (2018). Front. Behav. Neurosci. 12:153. doi: 10.3389/fnbeh.2018.00153

In the original article, there was an error.

In the second paragraph of the section Associations Between ME, Balanced, MS, and Music Preference, it is written that MS experience more music-induced chills. However, there is a spelling error and MS should be replaced by ME. A correction has been made to this paragraph which now reads:

Post-hoc analyses using repeated contrasts (and thus comparing ME to MS) show that MS more often reported actively engaging in musical activities (e.g., playing an instrument) $(p \leq 0.001)$, whereas ME more often reported experiencing music-induced chills while listening to music $(p \leq 0.001)$.

The authors apologize for this error and state that this does not change the scientific conclusions of the article in any way.

The original article has been updated.

Conflict of Interest Statement: The authors declare that the research was conducted in the absence of any commercial or financial relationships that could be construed as a potential conflict of interest.

Copyright (c) 2018 Linnemann, Kreutz, Gollwitzer and Nater. This is an open-access article distributed under the terms of the Creative Commons Attribution License (CC BY). The use, distribution or reproduction in other forums is permitted, provided the original author(s) and the copyright owner(s) are credited and that the original publication in this journal is cited, in accordance with accepted academic practice. No use, distribution or reproduction is permitted which does not comply with these terms. 